\title{
FENOMENOLOGIA JURÍDICA E A INTRÍNSECA CORRELAÇÃO COM AS SITUAÇÔES JURÍDICAS EXISTENCIAIS NA CONFORMAÇAO DOS NOVOS DANOS
}

\section{LEGAL PHENOMENOLOGY AND INTRINSIC CORRELATION WITH EXISTENCIAL LEGAL SITUATIONS ON NEW TORTS SHAPING}

\author{
${ }^{1}$ Ana Cláudia Corrêa Zuin Mattos do Amaral \\ ${ }^{2}$ Pedro Henrique Arcain Riccetto
}

\section{RESUMO}

Analisa os moldes atuais da fenomenologia jurídica aplicada às indenizações civis, com a ampliação de categorias clássicas a modalidades outrora ignoradas. Apresenta breve desenvolvimento histórico do direito subjetivo, até que se permita atingir o conceito de interesse juridicamente tutelável. Discorre sobre as novas modalidades de fenômeno jurídico

- a situação jurídica existencial e os negócios jurídicos existenciais - e a forma em que, por consequência, se permitiu falar, hodiernamente, em danos existenciais que transcendem a noção clássica de dano moral.

Palavras-chave: Responsabilidade civil, Fenomenologia jurídica, Situação jurídica existencial, Dano extrapatrimonial

\begin{abstract}
Analyzes the current form of legal phenomenology applied to civil torts, with the expansion of its classical categories to other modalities previously ignored. It presents short historical development of the subjective right, until it will achieve the concept of legal interest. Discusses the new forms of legal phenomenon - existential legal situation and the existential legal business - and the way in which, therefore, allowed to speak, these days, in existential damage that transcend the classical notion of moral damage.
\end{abstract}

Keywords: Civil liability, Phenomenology, Existential legal situation, Existential tort

\footnotetext{
${ }^{1}$ Doutora em Direito Civil Comparado pela Pontifícia Universidade Católica - PUC, São Paulo, (Brasil) Email: tutortreinamneto@gmail.com

${ }^{2}$ Mestre em Direito Negocial na Universidade Estadual de Londrina - UEL, Paraná, (Brasil).
} 


\section{INTRODUÇÃO}

A Suprema Corte italiana reinventou, na histórica Sentenza n. 500/99, os alicerces da responsabilidade civil ${ }^{3}$. Alterando-se a perspectiva, o dano passa a apresentar como objeto não só o direito que tenha expressa previsão legal - subjetivo -, mas sim consagrado como a lesão de qualquer interesse reputado legítimo, ou seja, merecedor de tutela jurisdicional. E isso repercute, de forma significativa, na jurisprudência de nossos tribunais superiores ${ }^{4}$.

Embora notável, a mudança não ocorreu da noite para o dia. Somente possível a nova construção teórica frente às necessárias alterações sofridas gradualmente pela fenomenologia jurídica. A partir do reconhecimento de que certos bens jurídicos passíveis de proteção constitucional somente seriam de fato resguardados quando superada a barreira rígida do direito subjetivo, tornou-se possível a concessão de proteção jurisdicional ao interesse jurídico, que, embora responsável pela produção de efeitos jurídicos, não encontrava-se abarcado pelo comando de determinada norma jurídica. Daí permitir-se a ampliação não só dos danos indenizáveis, decorrente daquilo que historicamente se colocou como "revolta dos fatos contra os códigos" (SICHES apud DINIZ, 2003, p. 57), mas também o surgimento da situação jurídica existencial e, após, do negócio jurídico existencial.

A noção do que é efetivamente o interesse juridicamente tutelado escapa, contudo, à doutrina civilística clássica. Os efeitos da mudança paradigmática somente expuseram a necessidade de se rever não só o conceito do dano em si, mas também do próprio instituto da responsabilidade civil.

$\mathrm{Na}$ tentativa desenfreada de se reconhecer a existência de situações fáticas merecedoras de ressarcimento, sob uma ótica até mesmo humanística, o julgador brasileiro classifica por vezes com atecnicidade quais os danos merecedores de tutela e a extensão dos demais pressupostos à indenização - reflexo decorrente de uma análise pouco criteriosa não só do interesse, mas do fenômeno jurídico como um todo.

\footnotetext{
${ }^{3}$ Para melhor elucidar a alteração de paradigma representada pelo julgamento italiano, recomenda-se a leitura do artigo de Ana Cláudia Côrrea Zuin Mattos do Amaral e Éverton William Pona, intitulado “Ampliando horizontes: expansão da categoria dos danos ressarcíveis como garantia da sustentabilidade jurídico-social nas relações privadas”. In: KEMPFER, Marlene; ESPOLADOR, Rita de Cássia Resquetti Tarifa. (Org.). Estudos em Direito Negocial e Sustentabilidade. 1ed.Curitiba: CRV, 2012, p. 9-42.
} 
${ }^{4}$ Não é incomum deparar-se com julgados do Superior Tribunal de Justiça em que se reconhece o dever de indenizar em face dos chamados "novos danos", como, por exemplo, a perda de uma chance. Alguns julgados serão analis ados no desenvolvimento do trabalho. 
A fim de apresentar subsídios ao julgador, a doutrina, valendo-se de categorias mais ajustadas à realidade fática e à ideia de autodeterminação, permite ressarcir aquele que viu sua existencialidade lesada, mas vai além: utiliza o reconhecimento dos interesses jurídicos para ingressar no âmbito dos negócios jurídicos ${ }^{5}$. Permite-se então o ingresso em novas categorias de dano indenizável, outrora não amparados pelo Direito Civil, motivadas por uma nova forma de analisar abstratamente o fenômeno jurídico.

Assim, ancorada no método dedutivo, a pesquisa se divide em três capítulos delimitados, buscando-se a consecução do objeto proposto a partir da análise individualizada das categorias de fenômenos jurídicos (direito subjetivo e objetivo, interesse jurídico e situação jurídica), a fim de demonstrar os impactos do atual paradigma fenomenológico nas novas espécies de danos ressarcíveis.

\section{A CLÁSSICA FENOMENOLOGIA: A RELAÇÃO ENTRE DIREITO SUBJETIVO, DIREITO OBJETIVO E DEVER JURÍDICO}

Indiscutível que os elementos da responsabilidade civil passaram por diversas alterações nas últimas décadas. As mitigações sofridas por tais elementos frutificaram não apenas em decorrência de desenvolvimento doutrinário, como também, em verdade, foram amplamente aceitas pela jurisprudência com o passar do tempo e, inclusive, pela lei, que passou a predizer a responsabilização objetiva em um número muito maior de situações do que as inicialmente previstas.

Alterou-se de maneira sensível o foco das indenizações, que agora prioriza a análise do dever de indenizar sob a perspectiva do lesado, que não deve ter, para obter o ressarcimento que the é devido, que transcender obstáculos descomedidos (LEVY, 2012, p. 29).

A erosão sofrida pelos elementos da responsabilidade civil ${ }^{7}$ não é o único fator a ensejar a ampliação do dano indenizável: uma análise fenomenológica permite afirmar que o

\footnotetext{
5 Para maior apronfundamento acerca da autodeterminação e negócios jurídicos existenciais, recomenda-se a leitura da obra "Testamento vital e autonomia privada: fundamentos das diretivas antecipadas da vontade", de Éverton William Pona.

7 O termo "ocaso" da culpa é utilizado por Anderson Schreiber em sua obra "Novos paradigmas da responsabilidade civil: da erosão dos filtros da reparação à diluição dos danos", embora não seja pacificamente aceito pela doutrina, porque poderia levar a crer que a responsabilidade subjetiva viria a ser extirpada do ordenamento jurídico.
} 
reconhecimento de tutela à categoria dos interesses legítimos (juridicamente relevantes) foi ponto fulcral ao reconhecimento dos novos moldes ressarcitórios, hoje já em adiantado estado de recepção pelo Poder Judiciário. Seria, então, um elemento de qualidade, de natureza substancial.

Adentrando-se ao fenômeno jurídico in abstrato, tem-se a possibilidade de que sobre fatos do mundo real incidam normas jurídicas. A ocorrência de um fato social cuja previsão se encontra em norma acaba por dotá-lo de juridicidade, qualificando-o, de tal forma, como fato jurídico (AZEVEDO, 1986, p. 31-32). Porém, alguns fatos sociais, embora dotados de relevância, não são abarcados por normas jurídicas - produzem efeitos jurídicos, mas, em razão da ausência de comando advindo de uma norma jurídica, não geram um direito subjetivo. Afastam-se desses últimos fatos ou situações do mundo real as ideias de sujeito de direito e de relação jurídica em sua acepção clássica, face à ausência do direito subjetivo que, quando jurídicos, deles decorrem (AZEVEDO, 1986, p. 32).

Previamente ao estudo do interesse jurídico, situado em vãos de ausência do direito subjetivo, necessário proceder a uma digressão teórica acerca da distinção entre direito subjetivo e objetivo, com a apresentação dos respectivos conceitos e principais características.

O direito objetivo, exterior ao sujeito, pode ser visualizado como o conjunto de normas impostas à conduta humana, autorizando ou não o indivíduo a fazer ou se omitir em relação a algo, com a prescrição de medidas de repressão no caso de violação de seu teor (DINIZ, 2009, p. 251). A permissão de o indivíduo agir conforme o direito objetivo, por sua vez, representa o direito subjetivo, e demonstra seu caráter de indissociabilidade com o direito objetivo, sem que um possa existir sem a figura do outro (DINIZ, 2009, p. 247).

O reforço do conceito de direito subjetivo encontra-se na ideia clássica:

Ao direito subjetivo contrapõe-se o dever jurídico, situação passiva que se caracteriza pela necessidade de o devedor observar certo comportamento (positivo ou negativo) compatível com o interesse do titular subjetivo. Nos direitos absolutos esse dever é geral, todas as pessoas devem observá-lo, como ocorre nos direitos reais e nos direitos da personalidade. [...] Nos direitos relativos, como nas obrigações, o dever é especial, competindo apenas à pessoa vinculada pela relação jurídica, como, por exemplo, o comprado e o locatário, em relação ao vendedor e ao locador. [...] O dever jurídico é, portanto, a necessidade de se observar certo comportamento, positivo ou negativo, a que tem direito o titular do direito subjetivo. (AMARAL, 2003, p. 149) 
Consubstanciando-se a relação com o dever jurídico, define-se ainda direito subjetivo como a ideia de um dever a ser prestado por outro indivíduo - ou, em outras palavras, o poder de ação oponível contra outrem, permitindo sua participação em uma relação jurídica, construída sob uma estrutura de bilateralidade. Faz-se um recorte dos elementos do direito subjetivo, que seriam (i) o sujeito, detentor de poder de exigir a ele outorgado pelo direito objetivo, porque toda vontade pressupõe a existência de um agente; (ii) o objeto, definido como o bem jurídico sobre o qual recai o exercício do poder jurídico, ensejando sua satisfação; e (iii) a relação jurídica, ou vínculo jurídico, que é, em síntese, o meio pelo qual se realiza o direito subjetivo, ou seja, é o elo que depende do ordenamento jurídico para efetivamente integrar o poder da vontade (PEREIRA, 2004, p. 39-45).

O descumprimento de tal dever jurídico associado à ideia de direito subjetivo enseja, sem maiores questionamentos, o dever do lesante de indenizar seu titular. Francisco Amaral (2003, p. 189) com clareza aduz que "o não cumprimento do dever geral de abstenção, nos direitos absolutos pode ensejar ato ilícito, enquanto nos direitos relativos consiste na infração do dever especial, gerando-se, em ambos os casos, a obrigação de reparar o dano, a chamada responsabilidade civil”.

Como consequência, se extrai, contrario sensu, que sobre o fato social não normatizado paira a circunstancialidade de não se poder criar ou gerar direitos (subjetivos), mas tão somente interesses, que, num primeiro momento histórico, não ensejavam o dever de indenizar pela falta da proteção concedida pelo direito objetivo.

Em tal sentir, os interesses acabam ficando afastados de proteção jurídica, que exige, num primeiro momento, um direito subjetivo que justifique a tutela jurisdicional; é onde surge o empecilho enfrentado pela justiça italiana que, somente no recente ano de 1999, iniciou o desmantelamento das barreiras entre os direitos subjetivos e interesses tuteláveis, que agora passam a ser objeto de proteção.

\section{NOVOS PARADIGMAS DO FENÔMENO JURÍDICO: A TUTELA DOS INTERESSES JURÍDICOS}

Na Sentenza $n .^{\circ}$ 500/99, a Suprema Corte italiana mencionou expressamente a superação dos tradicionais paradigmas da responsabilidade civil, limitados à existência de um 
direito subjetivo que pressupõe o respectivo direito objetivo. Nos fundamentados adotados na decisão, levantou-se que

$\grave{E}$ noto che la giurisprudenza di questa S.C. ha compiuto una progressiva erosione dell'assolutezza del principio che vuole risarcibile, ai sensi dell'art. 2043 c.c., soltanto la lesione del diritto soggettivo, procedendo ad un costante ampliamento dell'area della risarcibilità del danno aquiliano, quantomeno nei rapporti tra privati. ${ }^{8}$

O alargamento da ressarcibilidade a situações em que não há direito subjetivo ocasionou - na Itália em um primeiro momento, mas com importantes reflexos na doutrina brasileira - uma inevitável "expansão dos danos indenizáveis, concretizada pela ampliação do rol dos danos reparáveis, com o intuito de prestigiar o lesado, facilitando-lhe o acesso à indenização" (CHINELATO, 2002, p. 592). Em uma análise precisa do impacto da mudança paradigmática promovida pela sentenza no direito italiano, percebe-se o

danno determinato dalla realizzazione di un rischio normalmente connesso con il comportamento illecito, intendendo per normali anche i danni (cd. mediati o indiretti) che, sia pure in presenza di circostanze eccezionali, costituiscono, secondo il comune giudizio, la normale conseguenza di un determinato comportamento illecito (BONNANO, 2009,p.7)'.

Em linha de harmonização, complementa o citado autor que este novo enfoque do dano ressarcível permitiu no direito italiano a superação das diferenças entre os vários tipos de responsabilidade (pré-contratual, contratual e extracontratual), colocando na base das mesmas o comum denominador do fato ilícito, que representa a imputabilidade. Afirma ainda que tal sistema de responsabilidade civil permitiu incluir várias hipóteses de indenização de danos decorrentes do ilícito que antes, dada a rigidez do sistema, não era possível tutelar, ou, onde se admitia a tutela apenas como reflexo, como danos mediatos ou indiretos da lesão a um direito subjetivo (BONNANO, 2009, p.10).

\footnotetext{
${ }^{8}$ Em tradução livre: "É sabido que a jurisprudência desta Corte de Cassação erodiu gradualmente o caráter absoluto do princípio de que é ressarcível, nos termos do art. 2.043 do Código Civil, somente a lesão a direito subjetivo, progredindo a uma constante expansão da abrangência da ressarcibilidade do ato ilícito, pelo menos nas relações entre particulares"

9 Em tradução livre: dano representado pela implementação de um risco normalmente associado a um comportamento ilícito, como também os danos (chamados mediatos ou indiretos) que, em presença de circunstâncias excepcionais, constituem, segundo o senso comum, a consequência normal de uma determinada conduta ilícita.
} 
Confirmando tal ampliação, dentro da teorização dos novos danos, Kemelmajer de Cartucci (1995, p. 37) assevera que “[...] existe daño cuando se cause a outro algún perjuicio a su persona, a su patrimônio, o a sus interesses no reprovados por la ley", tornando explícito que o interesse não reprovado pela lei - jurídico, portanto - enseja dano, e segue, com a conclusão de que esse dano é passível de ressarcimento. As noções ora expostas também se baseiam em Francesco Carnelutti (1930, p 12-14), que afirma, ao definir, ainda que brevemente, o interesse:

Il danno riguarda sempre la situzione dela persona rispetto al bene, non il bene bene in sè. Appunto il concetto di lesione si attaglia all'interesse, non invece al bene (considerato al difuoridal suo rapporto con uomo). Questo è il motivo, per cuila formula può e deve essere definito più precisamente di cosi. [...] Perciò la nozioni di interesse, se há da essere uno dei fondamenti dela teoria giuridica, conviene che sai obbiettiva, non subbiettiva; che consideri l'interesse come qualcosa che existe fuori da noi, non in noi. Ciò che existe fuori da noi, e non è il bene stesso, è la curo di poterlo impiegare per la sodisfasione di um bisogno; questa situazione è l'interesse; la relazione, dunque, quaeinter est, tral'uomo e il bene. La fame è um bisogno; um pane è um bene; Poter mangiare il pane, questo è um interesse". ${ }^{10}$

Consolidado o instituto e sua potencial ressarcibilidade, nos casos de lesão, pode-se prosseguir com a afirmação teórica de que: para falar-se em dano injusto, necessária a lesão a interesse juridicamente tutelado na vida de relação (BIANCA, 2002, p. 978).

A omissão do ordenamento brasileiro quanto a tais situações ocasionou, historicamente, a chamada "revolta dos fatos contra os Códigos". O fenômeno da codificação não conseguiu abarcar a totalidade de fatos capazes de produzir efeitos jurídicos em textos legais, de modo que o engessamento ocasionado gerou um grave descompasso entre o mundo real e o ordenamento jurídico - e sofreu, com a repersonalização das relações privadas, movimento inverso: o de descodificação.

\footnotetext{
${ }^{10}$ Em tradução livre: Dano diz respeito sempre à situação da pessoa em relação ao bem e não ao bem em si mesmo. Precisamente, o conceito de lesão se relaciona ao interesse, e não com o bem (considerado fora de seu relacionamento com o homem). Por esse motivo, a fórmula deve ser simplificada à lesão de interesse. Não considero que o dano possa ser mais precisamente definido do que isso[...] porque a noção de interesse tem de ser um dos fundamentos da teoria jurídica e convém que seja objetiva e não subjetiva; que considere o interesse como qualquer cois a que existe fora de nós e não em nós. O que existe fora de nós não é o bem em si mesmo; é a capacidade de poder usá-lo para a satisfação de uma neces sidade. Essa situação é o interesse; a relação de interesse entre o homem e o bem. A fome é uma necessidade; o pão é umbem; poder comer o pão, este é um interesse.
} 
Face à ausência de um direito subjetivo, incabível falar-se na existência de sujeito de direitos, ou mesmo trazer o conceito clássico de relação jurídica. Não há dúvidas, porém, que eventos fáticos não normatizados - pela inexistência de direito objetivo correspondente, isto é, de um comando emanado da norma - criam situações jurídicas que circundam centros de interesse e que merecem tutela jurídica. Como visto, tais fatos não geram direitos, mas interesses, que não eram, outrora, chancelados pelo Estado por meios jurisdicionais, contexto que culminou em nova forma de se pensar o Direito Civil.

O descompasso entre o Code Napoleon e os anseios da sociedade, agravado por um ritmo de progresso social e um Judiciário literal, ocasionou problemas que o texto legal não era capaz de solucionar. Os movimentos de descodificação surgiram, em contraposição, como efeito necessário da constitucionalização do Direito Civil, que buscou, ainda que de forma reflexa, se afastar do sujeito de direito abstrato.

No Brasil, Luiz Edson Fachin expôs a teoria do estatuto jurídico do patrimônio mínimo, elevando a pessoa humana ao "epicentro dos epicentros". Justifica os novos paradigmas interpretativos, buscando-se solucionar o distanciamento historicamente proporcionado entre a norma e o indivíduo:

\begin{abstract}
A existência humana digna é um imperativo ético que se projeta para o Direito na defesa de um patrimônio mínimo. A pessoa natural, ao lado de atributos inerentes à condição humana, inalienáveis e insuscetíveis de apropriação, pode ser também, à luz do Direito Civil brasileiro contemporâneo, dotada de uma garantia patrimonial que integra sua esfera jurídica. Trata-se de um patrimônio mínimo mensurado consoante parâmetros elementares de uma vida digna e do qual não pode ser expropriada ou desapossada (FACHIN, 2006, p. 1).
\end{abstract}

A ideia reflexa da descodificação consiste em proteger as partes hipossuficientes das relações jurídicas de natureza privada (MARQUES JÚNIOR, 2013, p. 326), pela criação de microssistemas que orbitam não sobre a figura de sujeitos de direito abstrato, mas de sujeitos de direito alinhados às suas respectivas vulnerabilidades. Orlando Gomes (2001, p.. 108) ressalta que os microssistemas defrontam a unidade codificada porque apresentam filosofia própria e apresentam dinâmica própria, com critérios, influxos e métodos específicos.

Verifica-se uma profunda alteração, a um, na técnica legislativa, que passa a oferecer textura mais aberta, com a definição de objetivos concretos, distanciando-se do ideal de estabilidade e regulação para negócios - o que se confirma pela adoção de cláusulas gerais e 
conceitos abertos; a dois, passa-se a considerar uma função promocional do direito, e não apenas repressiva; e, a três, e fulcral para o tema ora tratado, que a humanização do Direito abriu margem para o legislador tratar não apenas de questões patrimoniais, permitindo-se a imposição de deveres extrapatrimoniais nas relações entre particulares, a fim de assegurar a personalidade e, em última análise, a tutela da dignidade humana (TEPEDINO, 2004, p. 3-5).

De tal modo, ressalta o aumento da importância desses movimentos com a relevância ora dada à dignidade da pessoa humana e ao mínimo existencial (FACHIN, 2006, p. 1), que interferiu inclusive na conformação da autonomia da vontade, que agora adquire novas feições ${ }^{11}$. O advento do pós-positivismo, que internaliza a construção alemã da força normativa da Constituição e permite a elaboração de uma teoria completa dos direitos fundamentais, aliado à constitucionalização do Direito Civil, deu impulso direto à proteção daquilo que viria ser visto como situação jurídica existencial (PONA, 2015, p. 187-190) - a situação jurídica advinda de um interesse legítimo e juridicamente relevante não cunhado de patrimonialidade e que teve grande relevância na nova configuração do direito dos danos.

Situação jurídica, enquanto fenômeno jurídico, enquadra-se como uma realidade jurídica pré-legal, existente independentemente de leis que a conforme. Daí decorre que nem toda valoração pelo Direito dá origem a uma relação jurídica - vide os interesses jurídicos, intimamente relacionados à situação jurídica; recorre-se, então, a um conceito mais abrangente, que é o de situação jurídica, capaz de abarcar não só as relações jurídicas, provenientes do direito subjetivo, mas qualquer valoração da realidade pelo ordenamento (ASCENÇÃO, 2002, p. 9-10)

Francisco Amaral (2003, p. 159) com cautela apresenta, em alguns traços, as novas perspectivas do fenômeno jurídico, ao afirmar que "outra figura que recentemente vem despertando interesse doutrinário é a de situação jurídica, com que se pretende substituir a de direito subjetivo". Em breve conceituação, explana que situação jurídico "consiste no conjunto de direitos e deveres atribuídos pelo Direito a uma pessoa, em determinadas circunstâncias", e informa que "a mais conhecida tentativa de substituir a noção de direito subjetiva pela de situação jurídica é de Duguit, para quem não haveria direitos subjetivos, mas sim situações jurídicas", de natureza objetiva e subjetiva, sendo o conceito do instituto

11 Ver também em Everton W. Pona, em "Testamento vital e autonomia privada: fundamentos das diretivas antecipadas da vontade", Curitiba:Juruá,2015, a abordagem quanto às novas conformações da autonomia da vontade, sob a ótica da dignidade da pessoa humana. 
"inseparável do de relação jurídica, que se pode também definir como o vínculo entre duas situações jurídicas correlatas".

Seguindo essa linha, pode-se frisar que situações subjetivas não tomam, obrigatoriamente, forma de direito subjetivo, e não devem fazer perder de vista a unidade do valor envolvido (PERLINGIERI, 2002, p. 156). Ainda, a separação entre subjetividade e personalidade permite a demonstração de situações jurídicas nas quais a ideia de direito subjetivo é insuficiente para tutelar a pessoa humana, abordagem teórica que culminará na chamada situação jurídica existencial:

\begin{abstract}
Expressam nada menos do que as dimensões da personalidade humana. A socialização impõe-se justamente para evitar-se um olhar obnubilado por interesses que obstruem, na realização de, por exemplo, uma atividade econômica, a plena construção livre da personalidade. O condicionamento do exercício de determinadas situações jurídicas subjetivas à observância da função social visa, justamente, à proteção da pessoa. (PONA, 2015, p. 191)
\end{abstract}

Assim, passa-se a exercer tutela por centros de interesses, podendo haver "relação juridicamente relevante entre dois ou mais centros de interesses sem que ela se traduza necessariamente em relação entre dois sujeitos" (PERLINGIERI, 2007, p. 114). Consideramse também, porém, as situações jurídicas vinculadas ao patrimônio, igualmente integrantes da categoria "situação jurídica".

A sintonia do movimento de repersonalização do direito privado com a progressiva relevância dada aos interesses jurídicos e situações jurídicas - inclusive existenciais - permitiu a pacificação da ideia de que a lesão a certos interesses deveria ser indenizável, ao mesmo tempo em que trouxe dificuldade de se fugir do subjetivismo do julgador que estabelece os limites do dever de indenizar e o quantum indenizatório - isso diante da inexistência de critérios mais delianeados para se definir o que poderia vir a ser enquadrado como interesse existencial dotado de relevante juridicidade; como situação jurídica existencial; e, num momento posterior, que poderia ser reputado como negócio jurídico de cunho existencial.

Tanto assim ou mais quanto o fato dessa diversidade de novos fenômenos jurídicos ser a responsável pela expansão dos danos indenizáveis. As lesões aos direitos da personalidade decorrem de uma cláusula geral disposta pelo artigo 11 do Código Civil que os 
elenca de forma enunciativa ${ }^{12}$, e não taxativa. Porém, há inúmeros outros interesses advindos da personalidade que possuem natureza existencial sem que ocorra um balizamento sobre os limites e possibilidades para que possam de fato estar inseridos nas relações ou negócios jurídicos tradicionais - e tais lesões acabam por ampliar não somente o espectro protetivo da jurisdição, mas, por decorrência, a abrangência da ressarcibilidade dentro do próprio Direito Civil - quando se pode afirmar então a relação entre esta nova visão do fenômeno jurídico como pressuposto daqueles que vieram a ser conhecidos como novos danos.

\section{DIREITO SUBJETIVO, INTERESSE LEGÍTIMO E NOVOS DANOS: PERMISSÕES TRAZIDAS PELA NOVA DINÂMICA DO FENÔMENO JURÍDICO}

O impacto causado pela constitucionalização do Direito Civil propiciou uma revisitação, e em alguns casos até mesmo uma releitura estrutural, às categorias do fenômeno jurídico. A humanização do Direito, levada a cabo por mecanismos de ordem constitucional e legal e até mesmo por eventos normativos em separado - como a descodificação -, permitiu a superação de uma normatização direcionada primordialmente à tutela do patrimônio. A consolidação de uma teoria dos direitos fundamentais,

em vez de apregoar tal conformação, têm por meta orientar a ordem jurídica para a realização de valores da pessoa humana como titular de interesses existenciais, para além dos meramente patrimoniais. O direito civil, de um direito- proprietário, passa a ser visto como uma regulação de interesses do homem que convive em sociedade, que deve ter um lugar apto a propiciar o seu desenvolvimento com dignidade. Fala-se, portanto, em uma despatrimonialização do direito civil, como consequência da sua constitucionalização. (CANOTILHO, 1993, p. 226).

A reformulação estrutural suportada pela regulamentação das relações privadas permite a congregação do patrimonialismo, destacado no Estado Liberal, e a proteção da pessoa humana e solidariedade social, atendendo-se, agora, à transposição político-cultural antes desconsiderada (BARROSO, 2006). Assim, no âmbito da responsabilidade civil, o novel paradigma deu azo a alteração substancial, erigindo-se "a sistemática extensão da tutela

12 O artigo 11 do Código Civil assim prevê: "Art. 11. Com exceção dos casos previstos em lei, os direitos da personalidade são intransmissíveis e irrenunciáveis, não podendo o seu exercício sofrer limitação voluntária”. 
da vítima, em detrimento do objetivo anterior de punição do responsável" (MORAES, 2006, p. 238).

Aliado às novas conformações constitucionais, o rápido desenvolvimento tecnológico, contraposto ao lento regime de normatização e organização das atividades sociais que o acompanham, exigiu, também, uma nova forma de se encarar o fenômeno jurídico e a dinâmica das indenizações (MORAES, 2010, p. 322). A obsolescência das respostas jurídicas para uma regulamentação satisfatória das novas relações sociais e de novos danos técnicos exigiu da doutrina uma reconstrução dos alicerces da responsabilidade civil, que envolve, enfim, um novo olhar aos interesses jurídicos.

O sobrepujamento dos óbices à tutela dos interesses jurídicos passa, portanto, por um primeiro momento, em que torna-se independente de um direito objetivo e do direito subjetivo dele diretamente emanado, antes de se discutir quais, dentre os interesses, são passíveis de ressarcimento e devem ser categorizados como novos danos. Assim, ressalta-se

\begin{abstract}
uma certa tradição na brevidade das disciplinas normativas e o amplo emprego de conceitos gerais, como "culpa", "estado de necessidade", "exercício regular de um direito", "dever geral de cuidado", "abuso de direito", e assim por diante. A própria noção de dano, entendida como lesão a um interesse merecedor de tutela, converte-se, a partir da libertação das amarras do direito subjetivo, em uma cláusula geral de impressionante amplitude. Diante de tudo isso, hoje, não são poucos os civilistas a sustentarem que a seleção dos interesses merecedores de tutela, para fins de aferição do dano, demanda a ponderação entre o interesse da vítima e o interesse do agente cuja conduta se afigura lesiva. Exige-se a avaliação "simultânea" e sintética", e não independente e estática" do comportamento lesivo e do interesse lesado. Conclui-se, neste sentido, que "o dano será injusto quando, ainda que decorrente de conduta ilícita, afetando aspecto fundamental da dignidade humana, não for razoável, ponderados os interesses contrapostos, que a vítima dele permaneça irressarcida. (SCHREIBER, 2009, p. 152)
\end{abstract}

Promove-se, portanto, uma alteração no modo de se visualizar o fenômeno jurídico inserido na responsabilidade civil, passando o interesse legítimo a se equiparar, em diversos pontos, com o direito subjetivo, dando, assim, ensejo ao giro conceitual destacado por Orlando Gomes, do ato ilícito para dano injusto (1980, p 108). Embora não se enquadre no cerne do trabalho, deve-se frisar que o sistema de aferição do interesse jurídico tutelável e sua qualificação e posterior quantificação ainda passa por relevante discussão doutrinária, e não estão igualmente assentadas nos tribunais pátrios. 
O atual panorama ressarcitório tornou-se possível pela própria ideia de dano extrapatrimonial, conceituado como "uma lesão a direito da personalidade" (MORAES, 2003, p. 165). Desse modo, adotando nosso ordenamento critério não-taxativo de enunciação dos direitos da personalidade - circunstância que permite ofensa a personalidade em diversos aspectos -, não se pode, como consequência lógica, querer-se enumerar os danos extrapatrimoniais, limitando-se a situações especificamente previstas pelo legislador ordinário.

Quer pelo "significativo desenvolvimento dos direitos da personalidade", quer pelas "vicissitudes inerentes a um instituto que só recentemente tem recebido aplicação mais intensa", aponta-se uma sensível ampliação do rol de circunstâncias em que o dano extrapatrimonial se faz reconhecido judicialmente (MORAES, 2003, p. 166). Na conjectura de ampliação genérica dos direitos da personalidade com o consequente reconhecimento de tutela jurisdicional às suas facetas, "independentemente de serem ou não consideradas direitos subjetivos, todas as vezes que se tenta enumerar as novas espécies de danos, a empreitada não pode senão falhar: sempre haverá uma nova hipótese a ser criada” (MORAES, 2003, p. 166).

O cenário pode ser vislumbrado sob o aspecto estrito do fenômeno jurídico, porquanto dele decorre e nele se insere. Realizando-se uma análise mais abstrata da ampliação do rol dos danos ressarcíveis, tem-se que

pode a relação de obrigação, no transcorrer de sua existência, muitas vezes em razão das vicissitudes que sofre, gerar outros direitos e deveres que não os expressados na relação de subsunção entre a situação fática e a hipótese legal, ou não indicados no titulo, ou ainda poderes formativos geradores, modificativos ou extintivos, e os correlatos de sujeição; pode, por igual, importar na criação de ônus jurídicos e deveres laterais, anexos ou secundários ao dever principal, ao qual corresponderão, por sua vez, outros direitos subjetivos, mesmo que não expressamente previstos nem na lei, nem no título". (MARTINS- COSTA, 2000, p.429).

Torna-se secundária, nessa ordem de ideias, a necessidade de conformação específica do fato social à descrição legal para fins de configuração do dever de ressarcibilidade. No âmbito da fenomenologia, a dignidade da pessoa humana - repisa-se - "alterou radicalmente a estrutura tradicional do direito civil, na medida em que determinou o predomínio necessário das situações jurídicas existenciais sobre as relações patrimoniais" (MORAES, 2006, p. 234), e deu nova significação ao interesse legítimo, permitindo a abertura de um leque de situações, que superam a patrimonialidade, a que outrora se concedia proteção menos efetiva. 
A releitura estrutural promovida pela responsabilidade civil pós-moderna permite uma abrangência de situações lesivas antes incompatível com a doutrina civilística tradicional e desconsiderada pela jurisprudência. Contudo, a modificação paradigmática gerada pela compreensão atualizada do fenômeno jurídico in abstrato, alinhada à relevância dos interesses jurídicos e ao reconhecimento de situações jurídicas existenciais, assentiu com a ordem constitucional vigente e resultou na proteção da personalidade humana em suas variadas acepções, além de sobrepor à clássica noção de ato ilícito a de dano injusto, com maior projeção e voltado à solidariedade.

\section{CONCLUSÃO}

A ausência de uma maior delimitação e de hipóteses de incidência não permitem conferir aos interesses jurídicos decorrentes da personalidade a natureza de direito subjetivo. Não se pode, contudo, negar-lhes relevância, tanto em face do quilate do bem jurídico posto, mas também em decorrência de uma consolidada teoria dos direitos fundamentais.

O giro hermenêutico chancelado pela Suprema Corte italiana na Sentenza 500/99 se mostrou campo aberto para a ideia de ser ressarcível toda uma categoria de fenômenos jurídicos que não eram inicialmente tutelados pelo ordenamento jurídico - os interesses juridicamente relevantes -, e permitiu que os reflexos no Direito brasileiro irrompessem um movimento de reconstrução da civilística clássica, agora atenta a existencialidade. Emergiram, com o evento, discussões acerca da situação jurídica, inclusive com proposições no sentido de superação do paradigma direito objetivo-direito subjetivo, e trouxeram, ainda, tipologias até então inexistes, como, v.g., a denominada situação jurídica existencial.

Assim, deixou o direito de olvidar-se diante de tais situações, permitindo o ressarcimento decorrente de lesões a interesses juridicamente relevantes e legítimos. A repercussão advinda da superação da barreira entre direito subjetivo e interesse jurídico possibilitou, no direito brasileiro, a progressiva aceitação de indenizações fundadas em danos num primeiro momento não indenizáveis, mas que hoje já começam a ser vistos de forma pacífica pela doutrina e jurisprudência, porque, e não só por isso, constitucionalmente embasados. 
A atual compreensão da fenomenologia jurídica, alinhada à nova realidade constitucional, deve ser vista como o meio que possibilita os novos danos ressarcíveis, distanciando-se do caráter exclusivamente patrimonial e com maior atenção aos valores ligados à pessoa humana.

\section{REFERÊNCIAS BIBLIOGRÁFICAS}

AMARAL, Ana Cláudia Côrrea Zuin Mattos do. PONA, Evérton William. Ampliando horizontes: expansão da categoria dos danos ressarcíveis como garantia da sustentabilidade jurídico-social nas relações privadas. In: KEMPFER, Marlene; ESPOLADOR, Rita de Cássia Resquetti Tarifa. (Org.). Estudos em Direito Negocial e Sustentabilidade. 1ed. Curitiba: CRV, 2012

AMARAL, Francisco. Direito civil: introdução. 5. ed. rev., atual. e aum. Rio de Janeiro: Renovar, 2003.

ASCENÇÃO, José Oliveira. Direito civil, teoria geral: relações e situações jurídicas. Coimbra: Almedina, 2002.

AZEVEDO, Antônio Junqueira de. Negócio jurídico: existência, validade e eficácia. 2. ed. São Paulo: Saraiva, 1986.

BARROSO, Lucas Abreu. Novas fronteiras da obrigação de indenizar e da determinação da responsabilidade civil. In: Questões controvertidas: responsabilidade civil. (coords.) DELGADO, Mario Luiz; Alves, Jones Figueredo. Vol.5. São Paulo. Ed. Método, 2006.

BETTI, Emílio. Teoria geral do negócio jurídico. Trad. de Fernando de Miranda. Coimbra: Coimbra Editora, 1969.

BIANCA, Cesare Massimo. Realtà sociale ed effettività della norma: scritti giuridici. Obbligazioni e contratti. Responsabilità. Milão: Giuffrè. 2002.

BONNANO, Claudio. La perdita di chance nel Diritto Privato". Brevi riflessioni: alcuni spunti dottrinali e giurisprudenziali. In: Rivista de Diritto dell'Economia, dei Transporti e dell'Ambiente. Vol. VII. 2009.

CANOTILHO, José Joaquim Gomes. Direito constitucional e teoria da Constituição. $6^{\mathrm{a}}$ ed. rev. Coimbra: Almedina, 1993.

CARNELUTTI, Francesco. Il dano e il reato. Padova. Ed. Padova. 1930.

CHINELATO, Silmara Abreu Juny. Tendências da Responsabilidade Civil no Direito contemporâneo: reflexos no Código de 2002. In: Mario Luiz Delgado; Jones Figueiredo Alves (Coords.), Questões Controvertidas - responsabilidade civil. p. 583-606. São Paulo: Método. 2006. 
DINIZ, Maria Helena. Compêndio de introdução à ciência do direito, 15. ed. São Paulo: Saraiva, 2003.

FACHIN, Luiz Edson. Estatuto jurídico do patrimônio mínimo. Rio de Janeiro: Renovar. 2006.

GOMES, Orlando. Introdução ao Direito Civil. Rio de Janeiro: Forense. 2001.

Tendências modernas na civil teoria da responsabilidade. In. Estudos em homenagem ao professor Silvio Rodrigues. São Paulo: Saraiva, 1980.

LEVY, Daniel de Andrade. Responsabilidade Civil: de um direito dos danos a um direito das condutas lesivas. São Paulo: Atlas, 2012

MARQUES JUNIOR, William Paiva. Influxos do neoconstitucionalismo na descodificação, micronormatização e humanização do Direito Civil. In: Revista da Faculdade de Direito, v. 34, n. 2, p. 313-353, Fortaleza. jul./dez. 2013.

MARTINS-COSTA, Judith. A boa-fé no direito privado: sistema e tópica no processo obrigacional. Sao Paulo: Revista dos Tribunais, 2000.

MORAES, Maria Celina Bodin de. A constitucionalização do direito civil e seus efeitos sobre a responsabilidade civil. Revista Direito, Estado e Sociedade, Rio de Janeiro - v.9 - n.29 - p 233 a 258 - jul/dez 2006.

Danos a pessoa humana: uma leitura civil-constitucional dos danos morais.

Rio de Janeiro: Renovar, 2003.

DINIZ, Maria Helena. Compêndio de introdução à ciência do direito. 20. ed. rev. e atual. São Paulo: Saraiva, 2009.

Curso de direito civil brasileiro: teoria das obrigações contratuais e extracontratuais. 27 ed. São Paulo: Saraiva, 2011.

PEREIRA, Caio Maio da Silva. Instituições de direito civil: contratos, declaração unilateral de vontade, responsabilidade civil. v. 3, 4. ed. Rio de Janeiro: Forense, 1978

PERLINGLIERI, Pietro. Perfis do direito civil. Trad. de Maria Cristina de Cicco. 2. ed. Rio de Janeiro: Renovar, 2002.

PONA, Everton William. Testamento vital e autonomia privada: fundamentos das diretivas antecipadas da vontade. Curitiba: Juruá. 2015.

SCHREIBER, Anderson. Novos Paradigmas da Responsabilidade Civil: da erosão dos filtros da reparação à diluição dos danos. 5. ed. São Paulo: Atlas, 2013.

TEPEDINO Gustavo. Temas de Direito Civil. $3^{\text {a }}$ edição. Rio de Janeiro: Renovar, 2004 